Historia

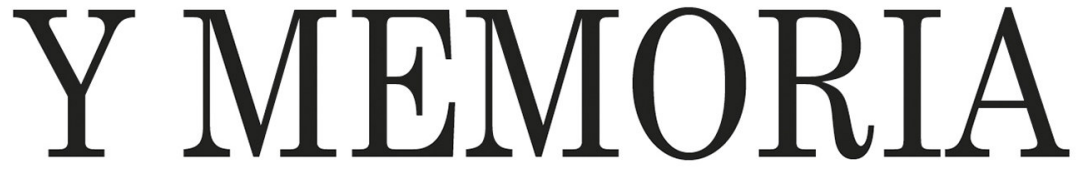

ISSN: 2027-5137 Julio - Diciembre, Año 2016 - Tunja, Colombia

Presentación del dossier:

Libros, lecturas y lectores en Colombia y América latina

Gilberto Loaiza Cano Páginas: 11 - 15 DOI: http://dx.doi.org/10.19053/20275137.5208

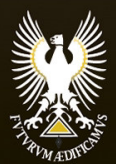




\title{
Presentación del dossier: Libros, lecturas y lectores en Colombia y América latina
}

\author{
Gilberto Loaiza Cano \\ Coordinador del dossier \\ Universidad del Valle - Colombia
}

DOI: http://dx.doi.org/10.19053/20275137.5208

En las revistas especializadas de las disciplinas reunidas en las ciencias humanas y sociales ha venido imponiéndose el método, muchas veces fecundo, del número monográfico. Eso ha servido para muchas cosas importantes, no solamente para sobreaguar, en el caso colombiano, ante los vaivenes de medición de nuestra inescrutable Colciencias. Ha servido, quizás principalmente, para convocar afinidades, para reconocer comunidades específicas de investigación por ciertos temas. Las revistas se han vuelto, entonces, en puntos de reunión, de vínculo más o menos indeleble entre aquellos oficiantes de varias disciplinas que coinciden en problemas de investigación. Este número 13 de la revista Historia $Y$ MEMORIA es otro buen ejemplo de ese esfuerzo afortunado por reunir bajo un tema las experiencias de investigación situadas en diversas partes; esta vez la convocatoria reclamó artículos que hablaran acerca de Libros, lecturas y lectores en Colombia y América latina.

El resultado reunido en esta revista me parece muy consistente; hubiese sido deseable una colaboración de algún investigador foráneo. Alguien desde Chile, México o Argentina donde sabemos que hay unas buenas tradiciones de indagación en las historias del libro y la lectura, acompañadas de los aportes, tal vez más sólidos, de lo que ahora se llama la "nueva historia intelectual". A pesar de esa ausencia notoria, 
el conjunto es muy significativo, informa acerca de lo mucho y muy diverso que hemos estado haciendo en Colombia; además logra decir que se trata de un terreno de inmensas posibilidades.

Algunos eventos recientes en Colombia han ayudado a que este número monográfico y otras publicaciones den cuenta de un núcleo cada vez más consolidado de investigaciones en torno a estos temas; precisamente, el profesor Alfonso Rubio, responsable del artículo que encabeza este dossier, ha liderado un seminario permanente sobre cultura escrita y ha organizado varias jornadas de reflexión y muy recientemente fue el editor de un libro colectivo que acoge a varios investigadores ${ }^{1}$. A inicios de este 2016, por iniciativa de Paula Andrea Marín, otra colaboradora en este dossier, hubo un evento internacional en el Instituto Caro y Cuervo en que se habló de historias de la edición, del libro y la lectura. De modo que han ido acumulándose antecedentes que permiten pensar en próximas obras muy definidas en torno a un universo disciplinar que va saliendo del ostracismo. ¿Tendremos pronto una historia del libro en Colombia o una historia de la opinión pública o una historia de la cultura impresa? No sé cuándo, pero sí está claro que hay un panorama cada vez más afianzado de estudios monográficos de muy buena calidad que pueden desembocar en algo mayores alcances temporales.

El primer artículo sirve para advertirnos que una historia del libro y la lectura no debe enajenar la historia de la escritura y, en este ejemplo, la escritura está vinculada con un proceso más complejo que vincula la historia del Estado racional moderno. El siguiente, cuyo responsable es el suscrito, refiere una tentativa de examen comparado del tránsito a un régimen moderno de publicidad basado en la libertad de imprenta. Luego viene, por obra de Robinson López Arévalo, un aporte a la historia de la biblioteca nacional de Colombia; el libro institucionalizado en la biblioteca principal del Estado constituye un ejercicio investigativo, por no decir

1 Alfonso Rubio, ed., Minúscula y plural. Cultura escrita en Colombia. (Medellín: La Carreta Histórica, 2016). 
que un reto múltiple en posibilidades. Seguir la historia de la formación y consolidación de la biblioteca nacional de un país significa reconstituir momentos de construcción de acervos, de tendencias según prioridades gubernamentales o de proyectos de difusión del libro dentro de las políticas culturales. El solo examen de cómo se formó una de sus colecciones nos remite, muy posiblemente, a un proceso de representación en que ciertos libros han ido ocupando un lugar tanto en la memoria colectiva como en los criterios de conservación de unos funcionarios. El orden o el lugar podían ser modificados según apetencias, caprichos, criterios de unos funcionarios sobre otros, y quizás eso diga mucho de cómo ciertas categorías de libros son entendidas por diferentes generaciones de funcionarios y lectores.

Hay un grupo de ensayos detenido en facetas de la historia de la lectura. Diana Paola Guzmán hace una apuesta interpretativa audaz; cree que la enseñanza de la lectura ha estado sistemáticamente vinculada, al menos en la temporalidad republicana, a una intención higienista. Me parece que posee un corpus documental muy sólido y una mirada transversal fuerte que le permite ver eso que alguien llamó "regularidad discursiva" en la que las citolegias ocuparon un lugar de afirmación de una voluntad de control sobre el cuerpo de los individuos. Mientras tanto, Cristina Gil Medina y Paula Andrea Marín se detienen en un grupo de publicaciones que, en sus respectivas épocas, fueron hitos de la producción impresa. La una estudia la importancia que tuvo, en ciertas publicaciones femeninas de la segunda mitad del siglo XIX, la formación de la mujer lectora. Agreguemos, para matizar el asunto, que la mujer fue objeto muy definido de interés de los publicistas conservadores y que, de adehala, los escritores conservadores fueron muy perspicaces en la creación de estrategias publicitarias para crear un público lector femenino o, quizás mejor, un mercado lector. Biblioteca de señoritas, al lado de El Mosaico y La Caridad, participó de los esfuerzos sostenidos por formar una biblioteca ideal del catolicismo en un momento de disputas asociativas y publicitarias con el liberalismo radical. Y contribuyó a preparar el horizonte de expectativa de obras canónicas del catolicismo 
triunfante en vísperas del ascenso del proyecto político de la Regeneración. Y Marín Colorado nos ayuda a comprender cómo la imagen en las publicaciones periódicas fue un anuncio certero de los cambios en la sensibilidad que hicieron parte del tránsito moderno en la Colombia de los primeros decenios del siglo XX; sobre todo que parece indicar la asunción de una etapa comercial nueva que avizoró la conquista de un mercado no necesariamente letrado. La investigadora acierta al percibir un desplazamiento en los géneros predominantes de escritura, acompañantes del impactante mensaje visual. Estamos ante nuevos hábitos de consumo lector y ante la formación de un personal escriturario que tendrá su nicho en las columnas de revista y periódicos que iban abandonando el tono de la ensayística política que había sido la forma de escritura predominante.

Los dos últimos ensayos -en un orden de artículos que privilegió la cronología y el tipo de análisis- tratan acerca de publicaciones periódicas que revelan el estado de aquellos grupos de individuos involucrados en la actividad publicitaria. Ha habido, desde los más remotos tiempos del periodismo, una relación muy estrecha entre una publicación periódica y la vida asociativa. Muchos periódicos son indicio de la existencia de un grupo más o menos disciplinado de individuos que tienen en el periódico o en la revista el medio de difusión de sus aspiraciones. El estudio de Jean Paul Ruíz Martínez y Cristian Salamanca Arévalo sobre La Estrella es el resultado del rescate de varios periódicos tolimenses del siglo XIX que ahora hacen parte del rico acervo documental de nuestra biblioteca nacional; es un ejercicio de recuperación para el análisis histórico de unas publicaciones que dan cuenta de la existencia de un activo personal político regional. María Teresa Álvarez Hoyos hace un examen semejante; pero se detiene en un grupo de individuos de mayor impacto en la vida pública, plasmado en una revista que atravesó varios decenios. El enlace de su estudio con la historia intelectual, con la prosopografía de un núcleo de escritores y con la sociabilidad cultural de una región del país es ostensible. La existencia de la Ilustración nariñense, entre 1924 y 1955, refiere un ritmo de vida muy particular y, sin duda, ofrece un 
invaluable apoyo documental como un mundo intelectual que nos parece confinado en una esquina del territorio colombiano sostuvo una revista cultural en medio de transformaciones, algunas muy cruentas, de nuestra vida pública.

Ahora bien, ¿qué deseamos los responsables o animadores de estos números monográficos? Que el número en mientes se vuelva referencia escolar, publicación de uso académico a la mano para otros especialistas y para jóvenes investigadores en busca de una visión de conjunto sobre una u otra zona de interés. Yo confío en que este número patrocinado por Historia Y MEMORIA sea de uso constante entre colegas y pupilos. Gracias a la profesora Olga Yaneth Acuña y al equipo de la revista por haber logrado que este esfuerzo colectivo haya llegado a esta culminación afortunada. 